\title{
Position Paper of the Portuguese Association of Chronobiology and Sleep Medicine Regarding Daylight Saving Time and its Impact on Circadian Timing System
}

\author{
Posição da Associação Portuguesa de Cronobiologia e \\ Medicina do Sono Relativamente à Mudança da Hora e \\ ao seu Impacto no Sistema Temporal Circadiano
}

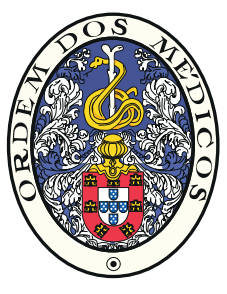

Miguel MEIRA E CRUZ $\triangle^{1}$, Sandra MARQUES ${ }^{1}$, Alcinda DAVID ${ }^{1}$, Cláudio LAUREANO ${ }^{1}$, Cláudio D'ELIA ${ }^{1}$, Carlos TEIXEIRA ${ }^{1}$, Amélia FELICIANO ${ }^{1}$

Acta Med Port 2019 Apr;32(4):258-259 - https://doi.org/10.20344/amp.11507

Keywords: Biological Clocks; Circadian Rhythm; Light; Seasons; Sleep; Sunlight

Palavras-chave: Estações do Ano; Luz; Luz Solar; Relógios Biológicos; Ritmo Circadiano; Sono

The Circadian Timing System (CTS) is an important regulatory system synchronizing internal medium with external clues. It is a dynamic multi-oscillatory system ensuring predictive adjustment of individuals to the active-rest cycle of day and night with a period of about 24 hours which results from the continuous earth rotation.

CTS is composed by a complex neurophysiological network with a master component (master clock), and several peripheral oscillators (peripheral clocks).

In mammals, the circadian master clock refers to a group of brain neurons located in the anterior hypothalamus and above the optic chiasm, and thus named suprachiasmatic nucleus (SCN). The SCN sends neural and humoral output signals to peripheral clocks located virtually in all body cells, organs and systems, in order to maintain synchronization between the main (central) clock and several peripheral clocks. Mammals and several other clock dependent organisms such as bacteria from the gut-brain axis are synchronized by this common mechanism defining an internal time. ${ }^{1}$

CTS is mainly regulated by the sunlight. Specific ganglionic cells within the eye retina are important for such regulation. These cells have photoreceptors that are highly sensitive to light intensity variations leading to melanopsin production. This environmental cue is then transferred to the SCN. Another key factor to the clocks synchronization is the production of melatonin in response to darkness (during the night). Conversely, the inhibition of such hormone occurs during the daylight hours of the day.

One of the most evident 24 hours rhythms in the body is the sleep-wake cycle which in humans is ideally coincident with the night and day, respectively. Additionally, wake time, alertness and attention, critical thinking and several other components of organic functions are also regulated on a circadian fashion depending of the functional integrity of the CTS.

Normal and pathological mechanisms are both regu- lated by circadian clocks synchronized with cells within our body. Therefore, any kind of chrono disruptive mechanisms may potentially affect both processes with impact on health. DST (daylight saving time) may adversely affect millions of people every year. The implementation of DST (daylight saving time) occurred for energy savings during World War I in order to lower the consumption of coal. However, nowadays there is not as much evidence to support the same goals and achievements, so it should be reviewed.

As predicted by the phase response curve to light ${ }^{2}$ applied to the DST process, when we travel one hour westbound, we are in synchronism with one-hour delay in sunrise and sunset in respect to our subjective internal time (SIT). This will promote a phase delay, which will help the process of resynchronization in the new time zone. In a similar way, when we travel one hour Eastbound, we will realize that sunrise and sunset occur one hour earlier with respect to SIT, which will induce a phase advance and therefore a quick response regarding to resynchronization in the respective time zone.

Nevertheless, DST simply determines an abrupt shift to one hour ahead, in the spring and one hour delay in the autumn without any correspondent changes in solar dynamics which makes the resynchronization process more complex. Furthermore, DST related changes are also associated with difficulties in the adjustment to natural seasonal oscillations.

Many biological and functional microstructures, such as genes, molecules and cells, have their own clocks that are under the influence of the master clock and of each other. Therefore, it is plausible that chronodisruption of the master clock evokes a wider effect in the peripheral oscillatory components, such as some immune cells that survey the emergence of cancer cells, inflammatory citokines and chemokines, several neurotransmitters and other mediators. ${ }^{3}$

The effects of DST are distinct depending on latitude

1. Portuguese Association of Chronobiology and Sleep Medicine. Lisbon. Portugal.

$\triangle$ Autor correspondente: Miguel Meira e Cruz. mcruz@medicina.ulisboa.pt

Recebido: 02 de novembro de 2018 - Aceite: 06 de março de 2019| Copyright @ Ordem dos Médicos 2019 
and chronotypes and seem to affect later chronotypes (affected in a higher degree) and morning chronotypes differently. ${ }^{4}$ In addition, people are also more sleep deprived while living on DST. ${ }^{4}$

More important, circadian clock disruption in a model of DST can lead to several physiological injuries, ${ }^{5}$ favoring cardiometabolic events ${ }^{6-8}$ and work place injuries. ${ }^{9}$

A final consideration should be made regarding the preference of clock permanent location. Standard (winter) time seems to be the best one since not only it favors light during the early morning and dark earlier in the night which is compatible to the more original and physiological clock but also because it is the most compatible with the solar time.

\section{REFERENCES}

1. Saper C.The central circadian timing system. Curr Opin Neurobiol. 2013;23:747-51.

2. Khalsa SB, Jewett ME, Cajochen C, Czeisler CA. A phase response curve to single bright light pulses in human subjects. J. Physiol. 2003,549:945-52.

3. Roeser K, Obergfell F, Meule A, Vogele C, Schlarb AA, Kubler A. Of larks and hearts -morningness/eveningness, heart rate variability, and cardiovascular stress response at different times of day. Physiol Behav. 2012;106:151-7.

4. Kantermann T, Juda M, Merrow M, Roenneberg T. The human circadian clock's adjustement is disrupted by daylight saving time. Curr Biol. 2007;17:1996-2000.

5. Meira e Cruz M, Acuña-Castroviejo D. Cardiometabolic impact of changing internal time during daylight saving time: a window for a deleterious role within sleep-related breathing disorders.Intern Emerg Med. 2018;13:1345-6.
Despite the lack of integrative knowledge in the scientific analysis about the effect of DST on CTS and health, there is sufficient evidence to admit that DST is not health-friendly and may seriously affect health related outcomes at different levels. Furthermore, a recent international consensus about the impact of DST on general physiology and health corroborate such findings concluding that DST has potential deleterious effects and should be discontinued. ${ }^{10}$

Therefore, the Portuguese Association of Chronobiology and Sleep Medicine defends a stable time, without changes along the year, with a preference by wintertime (standard time).

6. Manfredini R, Fabbian F, De Giorgi A, Zucchi B, Cappadona R, Signani F, et al. Daylight saving time and myocardial infarction: should we be worried? Eur Rev Med Pharmacol Sci. 2018;22:750-5.

7. Janszky I, Ahnve S, Ljung R, Mukamal KJ, Gautam S, Wallentin L, et al. Daylight saving time shifts and incidence of acute myocardial infarctionSwedish Register of Information and Knowledge About Swedish Heart Intensive Care Admissions (RIKS-HIA). Sleep Med. 2012;13:237-42.

8. Jiddou MR, Pica M, Boura J, Qu L, Franklin BA. Incidence of myocardial infarction with shifts to and from daylight savings time. Am J Cardiol. 2013;111:631-5.

9. Barnes CM, Wagner DT. Changing to daylight saving time cuts into sleep and increases workplace injuries. J Appl Psychol. 2009;94:1305-17.

10. Meira e Cruz M, Miyazawa M, Manfredini R, Cardinali D, Madrid JA Reiter R, et al. Impact of daylight saving time on circadian timing system an expert statement. Eur J Intern Med. 2019;60:1-3. 